\title{
The Main Participants of Innovation Climate Development (On the Example of the Russian Federation)
}

\author{
Safiullina A.M. \\ Odintsova J.L. \\ Kazan (Volga region) Federal University, 18, Kremlyovskaya Street, Kazan, \\ Repablic of Tatarstan, Russian Federation, 420008 \\ Zhilina N.N. \\ Shamsutdinova M.R.
}

Institute of Economics, Management and Law (Kazan), 42, Moskovskaya Street, Kazan, Republic of Tatarstan, Russian Federation, 420111

\section{Doi:10.5901/mjss.2014.v5n18p197}

\section{Abstract}

The article describes the main participants of innovation activity and innovation infrastructure, which includes such important categories as subject and object of innovation activity and the most important elements of innovation infrastructure. We attempted to display illustratively the basic economic relations that can be between the subjects of innovation activity, at the same time as the main participants are considered government, business and households. As binders subjects are allocated venture funds, technology parks, and business incubators. The state of innovation climate in the Russian regions can not be considered as favorable, because the order of interaction between government, universities (science), and business prevents it.

Keywords: innovation climate, innovation infrastructure, innovation activity, economic resources, individuals and organizations, research and technology park.

\section{Introduction}

Modern economies all over the world are highly dependent on the innovation activity of its individual subjects and objects. In the case of an enabling environment for this in the state are prerequisites for sustainable economic development. Unfortunately, in many countries the accumulated socio-economic problems do not suggest the presence of a favorable climate for innovation. The importance of studying the innovation climate due to the fact that it is a controllable factor in the innovation process which has a high synergistic effect on the national economy as a whole $[1,8]$.

\section{Theory}

A key component of the innovation climate is an innovative infrastructure that includes such an important category as subject and object of innovation.

As subjects of innovative activity are called organizations and individuals which implement and develop it, i.e. organize, lead, support and stimulate innovation.

1. In the Russian Federation subjects of innovative activity are:

1) individuals (citizens of the Russian Federation, stateless persons and foreign citizens ) engaged into the innovation activities;

2) legal entities ( Russian and foreign companies of any legal forms of ownership ), who are connected with innovations;

3) the owners of intellectual property , implemented and used in the process of innovation;

4) investors making investments in innovation;

5) organization ( entities) innovation infrastructure ( technology parks, techno, technology incubators , 
business incubators, venture capital funds, innovation funds and other organizations recognized by the subjects of innovation infrastructure;

6) public authorities and local governments involved in the coordination and management of innovation.

Individuals and legal entities are subjects of innovative activity for the duration of the activity.

Subjects of innovation can serve as customers, performers or investors of innovative projects and programmes or projects and programmes to support innovation [2].

Subjects of innovative activity for its implementation require different resources. For the purpose of summarizing the characteristics of the resources that the organization, industry, region, government can attract in the implementation of innovation, the concept of innovation capacity is used. Thus, the innovation potential is a combination of different types of resource, including material, financial, intellectual, scientific, technological and otherwise, used for realization of innovative activity $[3,6]$.

For the innovation activity implementation one need the innovative infrastructure which means the aggregate of subjects of innovative activity working in specific areas, including services for the creation and implementation of innovative products and services. By innovation infrastructure centres we understand technology transfer, innovation and technology centers, industrial parks, business incubators, training centers for innovation, venture capital funds, etc. (Fig. 1)

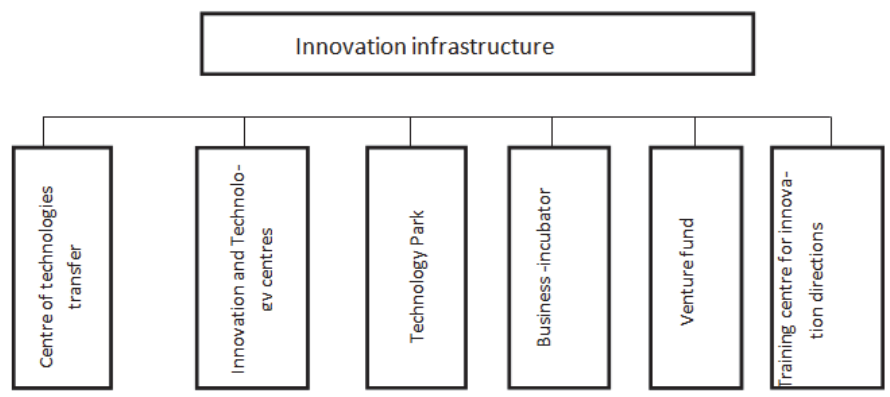

Fig.1. Elements of innovation infrastructure

The persons providing the conditions for innovation primarily should include public authorities, which set the overall direction of innovation, affirm innovative projects and programmes, develop the basic principles of the development of innovation in the field of science and scientific services, claim forms of public accountability, establish and record the organizations implementing innovative projects, etc. [4, 5].

\section{Results}

In accordance with the resolution of the Russian Government dated February 3, 1994 number 65 (as amended on the $12^{\text {th }}$ of December 1995 and on $6^{\text {th }}$ of March 1996.) Was established a fund to promote the development of small enterprises in scientific and technical sphere. Fund is established for the purpose of small business development in science and technology, the creation of small high-tech firms, business incubators, innovation, engineering centers, as well as to encourage competition in science and technology by providing financial support for a highly knowledgeintensive projects developed by small businesses [11].

The main objectives of the Fund are, in particular:

- To promote public policies of market relations formation in science and technology spheres by supporting the creation and development of small innovative business infrastructure;

- Participation in the development, examination, competitive selection and implementation of federal, regional programmes and projects with a demonopolization of the process of creation and development of new technologies;

- Support of the development and implementation of new technologies and "know-how" with the use of patents and licenses.

The objectives of the Innovation Council creation are the coordination of activities of main directions, the most effective development of innovative activity of the higher school in science and science education. The Council serves as 
an advisory body and its main task is to develop recommendations for the creation and implementation of innovative policy of Russian high school in the field of science and scientific services.

Possible forms of organizational structures that ensure effective interaction between science and industry are technopolises, technological and scientific parks, and scientific «incubators». These formations, the idea of creating which has been borrowed from the practice of industrialized countries, are designed to harmonize the relationship between academia, government and industrial centers.

The most powerful in its capabilities, requiring the mobilization of substantial material and financial resources, are technopolises. They represent the entire regional jurisdictions, which may include several industrial parks and incubator parks. In Russia, on the technopolis type was created, for example, Zelenograd.

Scientific and technological parks are structures of a smaller scale compared to technopolises. They usually are based on one or more universities, involving individual companies. An example is the industrial park "Novosibirsk", which was established by order of the President of the Russian Federation dated June 10, 1996 № 307. The creation of this technopark intended to advance development and acquisition of new competitive high technology, enhancing their impact on changes in the economic structure of the Novosibirsk region. The founders of the park "Novosibirsk" were GKI RF State Committee of Higher Education, the State Committee of the Russian Federation of the support and development of small business and the administration of the Novosibirsk region.

Scientific "incubators" or incubator type parks largely aimed in strengthening innovation and entrepreneurship. These multi-functional complexes with an extensive list of innovative and educational services firms clients, which, depending on its technological profile, buy these services, renting at the same time the incubator space. Upon lease expiration, the customer leaves the company incubator and begins an independent activity.

Their places among the subjects of innovative activity occupy the so-called small businesses that have opportunities on the commercialization of the results of scientific and technological activities. This is due, in particular, narrow subject specialization small organizational forms and their willingness to take a big risk.

Development Company involved into the innovation process by promoting the market promising inventions developed by individual inventors, as well as the production of small batches of individual products, which embodied the protected industrial property.

Venture (risk) company created for the purpose of bringing to the industrial implementation of the most "risky" innovations. They can be created as a temporary structure for solving a specific problem in practice or testing of promising technical ideas.

To the subjects taking part in the partial implementation of the innovation can be classified subjects of scientific and (or) and technical activities as defined in the Federal Law "About Science and State Science and Technology Policy." They can be scientists, experts of the scientific organization, workers of the scientific services, associations of scientists, scientific organizations, Academy of Sciences of the Russian Federation.

Academies of Sciences of the Russian Federation are public institutions created by federal authorities and financed by the federal budget. They include: the Russian Academy of Sciences, Russian Academy of Agricultural Sciences, Russian Academy of Medical Sciences, Russian Academy of Architecture and Building Sciences, Russian Academy of Arts.

Objects of innovation activity are:

1) the results of intellectual activity, containing technical and other useful information;

2) objects of exclusive rights associated with the creation of innovative products;

3) innovation and investment projects, programmes, services and activities related to the creation, development and distribution of innovative products;

4) innovative products;

5) financial assets, securities innovative organizations.

The above-mentioned features of innovation activity, characterize it in economic terms, as a process, a series of stages having content that passes scientific or technical idea of bypassing the "intellectual" and "material" stage of the innovation cycle. Obviously, the forms in which the innovative idea is transformed within each of the stages of the innovation cycle can be identified by fixing the final product on the "output" of the stage or another.

If we assume the object of activity the object on which the action of subject directed and the result of this activity in the form of the product, relating to its innovation the object will be manifested in the form of complex and collective notions of "intellectual product" and "ready goods". Further analysis of the objects of innovation we build just such an approach to the object definition.

Intellectual product as a result of innovation can be seen in a broad sense as a product of cultural production, designed to meet the social needs. In the academic literature there is substantial characteristic of the intellectual product. 
Its elements are called:

- Scientific and technical products, i.e. discoveries, hypotheses, theories, concepts, models (product of Fundamental Research), inventions, research and development activities, projects, prototypes of new technology, new products;

- Product information - software, radio and television programmes, etc.

- Cultural products.

It seems that such a gradation is devoid of any criterion that can serve as a basis for the classification of certain products of intellectual production.

As one of the possible classifications, eliminating this deficiency may be the following system of distribution of the objects included in the concept of 'intellectual product'.

All potentially possible results of intellectual activities are divided into two groups of objects that differ from each other by whether they have legal protection or not.

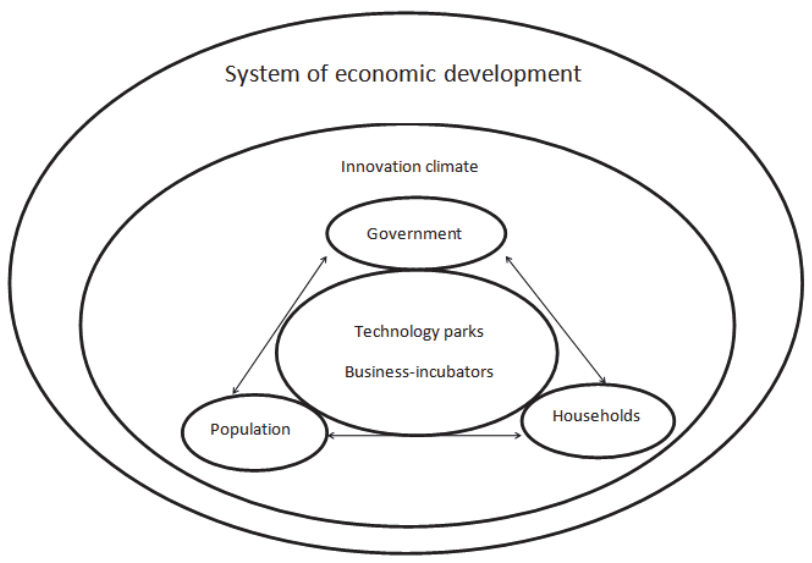

Fig.2. The main connections between the economic activity participants.

Innovative activity, considered as a process is not completed creating intellectual product, which, in essence, is the subject of an ideal. On developmental stages and technological developments that ideal object must be embodied in tangible media. Embodiment can be implemented by designing a new product or a sample of a new material, and the design documentation on them, or by developing new manufacturing techniques are known products or materials. However, data on the stages of the innovation cycle, it is possible the creation of objects whose appearance is more typical in the stages of basic and applied research - inventions, utility models, industrial designs, copyright works, etc [3, 11].

State - is a catalyst for innovation through targeted funding, allocation of critical technologies sector, it should guarantee to a private investor, to any no budget funding that legal rights will be stable and enduring. Formed by state innovation system consists of a set of economic subjects, as well as government and public institutions, which are in the process of fulfilling their institutional functions create conditions for promoting innovation and aim to ensure implementation of the federal and regional innovation strategies at the micro and macro levels, which ultimately contributes to the establishment and development of innovation climate.

There was an attempt to display illustratively the basic economic relations arising between the subjects of innovation, at the same time as the main participants are proposed government, business and households. Also as binders subjects are allocated venture funds, technology parks, business incubators $[7,9,10]$.

\section{Conclusions}

Thus, the state of innovation climate in the Russian regions can not be considered as favorable, which prevents the change of interaction order between government, universities (science), and business. The state is the main subject, creating a favorable innovation climate. It defines the strategic and operational direction of economic development, the main tasks and methods of their solutions, promotes the development of science, including the application and the 
preparation of scientific and engineering personnel, through the implementation of public procurement provides an initial demand for many innovations that later are widely used in the economy country etc.

\section{References}

Hadiullina, G.N., Nugumanova, L.F., Bagautdinova, N.G., Averiyanov, B.A. Transformation of the households functions in the modern Russian economy // World Applied Sciences Journal, 27(13), 2013, 111-115.

Carlsson, B. Internationalization of Innovation Systems: A Survey of the Literature. Research Policy.35(1),2006.pp.56-67

Etzkowitz, H.(2006). "The new visible hand: An assisted linear model of science and innovation policy", Science and Public Policy,Vol.33,No.5,June,pp,310-320(11)

Shaidullin R.N., Ulesov D.V., Shigabieva A.M. and Safiullin L.N. Innovative Infrastructure in Post-Industrial Society/l World Applied Sciences Journal, 27(13), 2013, pp. 180-183.

Bagautdinova, N.G., Novenkova, A.Z., Sarkin, A.V. Quality management system formulation and implementation as a factor of enhancement of the university role in the local development // World Applied Sciences Journal, 27(13), 2013, 38-42.

Leydesdorff, L. (2006).The Knowledge-Based Economy: Modeled, Measured, Simulated. Boca Raton, FL: Universal Publishers.

Ulesov D.V., Shigabieva A.M., Maratkanova E.M. and Shaidullin R.N. Information Infrastructure of Small Business Development// World Applied Sciences Journal, 27(13), 2013, pp. 193-196.

Whitley, R.D. (2001).National Innovation Systems. In N. J. Smelser \& P.B. Baltes (Eds.), International Encyclopedia of the Social and Behavioral Sciences (pp.10303-10309). Oxford, UK: Elsevier.

Gainova R.A., Shaidullin R.N., Safiullin L.N. and Maratkanova E.M. Infrastructural Component in Maintenance of Competitiveness of Region// World Applied Sciences Journal, 27(13), 2013, pp. 97-101.

Panasyuk, M.V., Safiullin, L.N., Pryadko, I.A., Anopchenko, T.Y. Classification of large and socially important enterprises of the region by the levels of their economic solvency // World Applied Sciences Journal, 27(13), 2013, 140-144.

Safiullin, M.R., Elshin, L.A., Prygunova, M.I., Galyavov, A.A. (2013). Complex Analysis of Prospects of the Volga Federal District Regions Development: Methodology and Practice. World Applied Sciences Journal 27, 4, 508-511. 
